\title{
Trends in Media and Communication Research in Specialized Scientific Arab Journals: An Analytical Study
}

\author{
Mohamed Chettah
}

\author{
Muhammad Noor Al Adwan \\ College of Communication and Media, \\ Al Ain University, P. O. Box: 112612, \\ Abu Dhabi, UAE
}

DOI: https://doi.org/10.36941/ajis-2022-0035

\begin{abstract}
This paper deals with media and communication research trends in Arab countries through specialized scientific journals. It presents an analytical study that monitors and analyzes media and communication research trends through a sample of specialized scientific university journals from some Arab countries. The study concludes with a number of results, the most important of which are:-Reliance on the questionnaire as a tool for data collection in research (36.09\%), followed by content analysis at a rate of $24.26 \%$. -A large percentage of published research (70.1\%) lacks scientific theories and approaches. -The predominance of individual research $(76.92 \%)$ compared with joint research with bilateral research reaching $21.89 \%$, and group research not exceeding $1.18 \%$ of the total sample research. -The interest of the published research was first in studying the content (36.98\%), then the audience (19.23\%), then the impact (13.31\%), with a lack of research that dealt with the communicator and the medium. -The journal papers that formed the corpus of this study are showing an increasing interest in new media (21.89\%) compared with a decreasing interest in traditional media.
\end{abstract}

Keywords: Trends, Media and Communication Research, Scientific journals, Analytical study

\section{Introduction}

The scientific journals specializing in media and communication research represent one of the most significant tools leading scientific research efforts and activities in this field of knowledge in Arab countries. A number of colleges, departments, centers, and associations publish a number of specialized scientific journals that focus on scientific research and studies in media and communication sciences, as well as on the presentation of new publications and theses for master's and doctoral degrees in the respective colleges and departments. The specialized scientific journals hold a significant rank in the scientific and research record of universities. This is through their role at local, regional, and international levels.

The history of specialized scientific journals in Arab countries stretches back for more than three decades. However, it is noticeable that research and studies performed on the accumulated knowledge are limited, and the available studies, within our survey on the research heritage in this 
aspect, are overwhelmingly local and limited to the study of certain areas, such as the trends of research and theses in media and communication during a certain period.

Accordingly, this study is a scientific attempt to find an answer to a fundamental question: "What are the research trends in media and communication sciences in the Arab countries, through an analysis of a sample of specialized scientific university journals?" This question has underlying sub-questions about the quality of such research, the theoretical approaches adopted thereby, the scientific research tools used, the language of research, and the media and communication areas addressed.

\section{Study Concepts}

\subsection{Media and Communication Research}

In recent years, many researchers and those interested in media and communication have combined both concepts of media and communication, and used the concept of communication to denote all human activities used to convey messages, of whatever content and means of conveyance, to deliver specific content for media or influence purposes.

Modern communication technologies have put an end to the interactive, immediate, and participatory era of one-way messages, and a number of studies have addressed this issue. (Dacheux, 2009). Likewise, there is a variety of trends regarding the relationship between media and communication, including media and communication research. Some consider media and communication in a certain way, claiming that "communication is a process and media is its content", including Escarpit Robert and Mayet. Meanwhile, some talk about a "hostile and integral relationship", including Bougnoux and E Dacheux. Others consider media and communication as two multidisciplinary fields which have the same purpose, including Olivier B. The latter group, currently prevailing, talks about the "unity of media and communication sciences", including B Miège. (Dacheux, 2009). It can be stated that the field of media and communication sciences is the most dynamic scientific and cognitive field, as it is witnessing profound developments and transformations, mainly due to the information revolution and the profound social and cultural transformations experienced by humankind at the beginning of the third millennium. (Walter, Douyère, Bouillon \& Ollivier-Yaniv, 2009). Accordingly, media and communication research includes: "All scientific and research efforts that deal with all elements of communication process, namely the sender, message, receiver, means, confusion, influence, and reaction, within specific scientific approaches and methods, using tools for testing and measurement, in order to get scientific results that help (in) identifying all communicative phenomena, and ultimately developing communication plans and strategies that contribute to the general efforts to develop and improve the society".

\subsection{Specialized Scientific Journals}

Several lexicons and dictionaries of media and communication sciences define "journal" as: "A newsletter with a cover that is issued regularly and contains various reading material" (Walken, 1986). It is derived from the French word "', meaning "a shop", and is also called, in English, "', meaning "to reconsider" (Ezzat, 2008).

Both previous names refer to the nature of the journal in terms of content and function, highlighting the diversity of topics and contents - hence "shop" or "store" - and the reviewing of events and topics through explanation, analysis, and interpretation, as in the term "review". (AL Khalaifi, 2008) The journals vary in terms of their content, audience, ownership, and regular publication. The Encyclopedia Britannica defines "journal" as a "periodical", "a printed or digitally published collection of texts (essays, articles, stories, poems), often illustrated, that is produced at regular intervals". (Encyclopedia Britannica,2020). The scientific journals trace their history back to the middle of the 17th century in Europe, where the first English journal was "Philosophical 
Transactions of the Royal Society of London" published by Henry Oldenburg. In France, the first scientific journal was published in 1665 under the title "Journal des Scavans", which subsequently became, from 1830, "Le journal des Savants". "Joelle Devillard" defined a scientific journal as "A serial bulletin that is published regularly under a registered title and (which) contains a number of topics (research and articles) reviewed by a reading committee according to certain scientific standards" (Devillard \& Marco, 1993).

\section{Literature Review}

The researcher intended to conduct a survey on the literature reviews in this field, in order to explore the achieved results and to seek guidance from some of them in this study. Among the studies on this topic are the following:

A study by Shukria Kookz Al-Sarraj, under the title: Trends of Scientific Research in the Specialized Journalism, Journal of the Media Researcher as a Model-Survey Study. The researcher selected a specialized academic journal of the "third level". (Al-Sarraj, 2018).

Through the analysis and surveying of content, she got a number of results, including:

1. The Journal (Journal of Media Researcher) included theoretical and applied research. The applied research amounted to $56.37 \%$, while the theoretical research represented $43.62 \%$.

2. The individual research represented $79.39 \%$, a percentage higher than that for joint research.

3. The research on media and communication represented $28.18 \%$, higher than those for other specializations, namely journalism, radio and television, public relations, the Arabic language, and the media.

4. The survey approach was used by $56.96 \%$, the descriptive approach by $36.96 \%$, and the historical approach by $3.63 \%$.

5. The percentage of male researchers was higher than that for females, amounting to $69.40 \%$ and $30.59 \%$.

6. The study revealed that $86.66 \%$ of published studies were not based on a theoretical approach.

The study was important because it dealt with a specialized academic scientific journal, one of the sample journals covered by our study, which permitted the making of some comparisons through analyzing and interpreting the results in part of the study.

A study by Ahmed Falaq and Khaled La'lawi, under the title: "Methodological Problems in the Doctoral Thesis of Media and Communication Sciences in Algeria" (Falak \& La'lawi 2018). The two researchers started with the idea that doctoral theses on media and communication sciences in Algeria have several shortcomings which, in their viewpoint, are due to "practicable scientific accumulations" and "mental and cognitive" errors that require the collective effort of specialists to review and find appropriate solutions. Such shortcomings include:

1. The problem of the cognitive belonging of topics: This problem arises from the widespread belief that the social phenomenon is not exclusive to a certain science. Therefore, researchers engage themselves in topics irrelevant to media and communication sciences, leading to the loss of "identity of specialization". The study places responsibility on those in charge of higher education matters, through considering it as a human sciences specialization instead of a social sciences subject or through considering it as a stand-alone specialization.

2. Ignorance of Paradigms: The ignorance of paradigms, or all-prevailing theories, in this particular field led to the dispersion of research efforts and to the inability of research to realize the desired results.

3. The problems of shortcomings in approach, methodologies, and tools: The study concludes that the doctoral theses have procedural errors, the most prominent of which is the inability to differentiate between methodology and approach, and between methodology and tool. 
4. The overuse problem of " questionnaire: Many doctoral researchers think that scientific research may not be valid without a questionnaire", which is misused and misapplied in many cases. This fact is confirmed by the study conducted by "Muhammad Shoman" and this will be discussed later (Shoman, 2004).

5. The problem of reading and questioning: The study notes that the lack of knowledge accumulation among researchers turns this reading and interpretation into a mere "superficial digital reading" of the results.

The study provided a theoretical background based on scientific observations through readings of a number of theses and dissertations, concluding that it is necessary to raise real questions, and to hold workshops on such problems, in order to achieve a qualitative leap in scientific research at this level of education and in this type of specialization.

A study by Aicha Kaabach, which is entitled "Trends in Electronic Media Research in Algeria from 2005-2010 - Analytical Study" (Kaabache, 2016).

The study analyzed the content of $\mathbf{2 5}$ university theses completed at the University of Algiers from 2005 to 2010. Using a number of analysis categories, including the topics of completed theses, the theoretical approaches used, the methodologies adopted in the selected samples, and the tools used in data collection - such as content analysis, questionnaire, interview, and observation - the study attained a number of results, as stated briefly below:

1. Diversity of theses' interests, including the uses and influence of, and comparisons between, electronic mass media.

2. Lack of clear theoretical approaches in the sample of theses selected in the study.

3. Adoption of more than one methodology for the study of media phenomena.

4. Use of more than one tool in collecting data for the study.

We chose this study as it selected a sample of theses, forming one of the tools through which we can track and monitor trends of scientific research in this specialization, in addition to specialized scientific journals, as is the case in our study.

- A study by Syed Bakhit, under the title: "Recent Trends in Journalism - A Survey and Critical Review of the Most Prominent Trends Prevailing in Journalistic Studies" (Bakhit, 2010). The study starts by indicating the increasing interest in journalism studies in light of the changes in media and communication, the information revolution, and many conferences in this field. Such interest has led to the emergence of several research groups calling for the critical review of theoretical and methodological aspects of completed journalistic studies.

The study came to a number of conclusions, the most important of which are:

1. The scope of studies is expanding with the expansion of business and the increased number of periodicals and periodic conferences in this field.

2. The number of journalistic studies is steadily increasing worldwide.

3. The initial studies are interested in analyzing content, audience uses, and use processes.

4. Some research fields have turned to new paths, and a number of researchers have turned to new research fields, leaving their previous field behind, as a result of the influence and attraction of modern communication technologies and their phenomena as they affect the field of journalism.

5. Communication and information technologies are having a positive and significant impact in terms of providing information, facilitating access to contents for analysis, and facilitating communication and discussion among researchers on a number of journalistic research topics.

6. New topics, such as the integration of mass media and new journalism genres, are being discovered on social media networks and sites.

This study is one of the most important modern research studies in the Arab region, seeking, through research and analysis, to define the features and trends of research in the field of journalism, and providing scientific material and results that can be relied upon in our study.

- A study by Syed Bakhit, under the title: "Theoretical and Methodological Problems of Social 
Media Research - An Analytical Reading" (Bakhit, 2016). This was conducted by the same researcher as a result of social media being a new communication phenomenon that raises theoretical and methodological problems for future research.

After discussing the prevailing trends, the study identified the most important theoretical and methodological problems in research and studies on social media (representing the main problem in the study), including:

A number of studies and pieces of research in this new field lack theoretical grounds capable of explaining the social media phenomena.

An absence of new models and theories to address all topics concerning social media.

The researcher came to a number of conclusions, including:

1. It is important to deal with social media and new media as new sciences.

2. Multiple and flexible approaches should be employed in studying the social media phenomenon.

3. New and advanced research tools should be developed, using new technologies, making use of the technical solutions provided thereby in studying the topics of this research field. A matrix of the new research issues in this new field should be developed (Bakhit, 2016).

- A study by Hosni Mohamed Nasr, under the title: "Trends in Research and Theorization in New Media - An Analytical Study of Scientific Production Published in Refereed Journals". Through the analysis of a sample of scientific research items published in refereed scientific journals, the study aimed to explore the reality of theorization and research in new media, and to map the priorities of research interest agenda in this field. It aimed to do this by reviewing the theoretical applications used in addressing the new media topics, thereby achieving an accumulation of knowledge that would benefit researchers and those interested in developing new scientific visions for new media in the Arab region and across the world.

The researcher summarized the results by answering the questions included in the study, as follows:

1. Five new concepts were introduced from the studies on new media, namely: cyberspace, virtual community, interactivity, hypertext, and multimedia. (Nasr, 2015).

2. The theories most used in research and studies on new media were determined: Agenda Setting and Building Theory, Uses and Gratifications Theory, Diffusion of Innovation Theory, and Knowledge Gap Theory.

3. The only theory that the communication researchers agreed was new was "Mediamorphosis", developed and published by (Roger Fidler, 1997) to explain the relationship between new and traditional media.

4. The study revealed that the most prominent trends and areas of research in future new media were New Media Credibility, Internet Addiction, and Depression.

The study reached a number of general conclusions, from which one can start to study a number of the research problems of new media, taking the following two observations into account:

- At present, it is no longer true that it is difficult to provide Arabic research and this is substantiated by our study wherein all analyzed research was obtained from the sample websites.

- It cannot be accepted and admitted that most research published in Arabic journals is a reflection of research published in English periodicals.

- A study by Thuraya Ahmed Al-Badawi, under the title: "Theoretical and Methodological Treatment of User Participation in the Digital Public Sphere - a Critical Analytical View of Recent Scientific Trends". (Al-Badawi, 2015) The study analyzed research and studies published on the new media in Arabic and foreign languages and tracked the latest developments in research on new media. The researcher analyzed a sample of literature and research from 2000 to 2014, including 87 Arabic items and 57 pieces of foreign literature and research. The study aimed to answer a major question: Have communication technologies 
produced intellectual and methodological approaches for the citizen user, or borrowed the approaches and methods of traditional means and adapted them to the nature and characteristics of digital communication technologies? Regarding such a question, the researcher reached the following results:

- Theoretical Level: The study concluded that foreign studies outclassed their Arabic equivalents in creating some intellectual approaches for the new media context.

- Methodological Level: The researcher mentioned that most Arabic studies were characterized by the descriptive aspects of digital public space, while most researchers used a set of traditional methodological tools, few researchers intended to use tools consistent with the new public space (the Internet), and other studies combined both traditional and new tools in dealing with this field. (Al-Badawi, 2015).

- A study by Nasr El-Din Layadi, under the title: "Scientific Research in Media and Communication Sciences in the Arab Region and the Absence of a Conceptual Horizon" (Layadi, 2016). In this study, the researcher addressed the deficiency of media and communication research in the Arab region, ascribing this to the following causes:

- The scientific research in this field of knowledge relies on theories that have framed research in the field of social and human sciences.

- The scientific research in this field depends on Western theories.

The study focused on the dependency of Arabic research in media and communication sciences on Western schools without benefiting from other contributions of such schools, as is the case with research in the Maghreb countries, which failed to benefit from the contributions of social constructivism in studying communicative phenomena. The same applies to the Mashreq countries where research on media and communication failed to benefit from the contributions of the hermeneutical school.

The study conducted by Nasr El-Din Layadi conforms with the study conducted by Awatef Abdel Rahman on "Media Research in the Arab World - Egypt as a Model" (Abdel Rahman, 2002). In this, she discussed the theses of the dependency school, and classified researchers in this field as either committed or opportunistic researchers. She sought to provide a guide to commitment in media research. In her opinion, this commitment should be to specialization and to the scientific or research community to which the researcher belongs, from the perspective of the organic intellectual (Abdel Rahman \& Seddik, 2019).

Among comparative studies in this field, we may refer to the study conducted by Mahmoud Abdel Raouf Kamel, under the title: "Trends in Journalism and Media Research in America and Egypt - An Analytical and Exploratory Comparative Study of the American Journalism and Media and the Egyptian Journal of Media Research" (Kamel, 2007). In this study, the researcher depends on the idea that the study is not a critical and evaluative study of the literature published in both journals; rather, it is a comparative analytical study of the research trends in both journals. The study relies on a comprehensive survey of the issues of both journals from 1989 to 2007 , a total of 18 issues. The study concludes with a number of results, the most important of which are:

1. The American journal has a more regular publication than the Egyptian one, and is of a higher quality and coordination in terms of print and production.

2. Both journals are similar in terms of research content, with print media research topping the list of published research, followed by television and the Internet.

3. Both journals are similar in terms of the academic degrees (pre-professorship) of the researchers and the percentage of female researchers.

4. The American journal has a higher percentage of joint research (research teams and groups), amounting to $47.7 \%$ of the total published research, compared with $2.3 \%$ for the Egyptian journal (a result confirmed by this study), with joint research in the (Egyptian) Media Research Journal not exceeding 8.64\% (Roger, 1997).

Moreover, Muhammad Shoman conducted a study under the title: "Problems of Discourse Analysis in Arab Media Studies - Egyptian Studies as a Model" (Shoman, 2004), aimed at identifying 
the main features of discourse analysis schools in different disciplines, trying to uncover the most important cognitive and methodological differences between such schools, and determining the accuracy and clarity of concepts and procedures used in discourse analysis in Arabic studies.

\section{Methodological Framework of the Study}

\subsection{Objectives of the Study}

The study aimed to identify the trends of media and communication research in specialized university scientific journals, and sought to achieve a number of scientific objectives, including:

1. Identifying the reality of scientific research in media and communication sciences in Arab countries.

2. Identifying the development of scientific research in media and communication sciences in Arab countries.

3. Identifying the changes That are occuring in the media and communication field.

4. Identifying the future of media research through analyzing and interpreting the results of the study.

5. Achieving scientific addition and accumulation in this field in the Arab region.

\subsection{The Study's Questions}

The study depended on a major question: "What are the trends of research in media and communication sciences in the Arab countries, through a sample of specialized scientific university journals?" Such a question includes the following sub-questions:

1. What is the rate of research published in the journals subject to the study?

2. What are the types of research and studies published in the sample journals subject to the study?

3. What are the tools used to collect the data of studies and research published in the sample journals subject to the study?

4. What are the most important theories and approaches used in the research and studies published in the sample journals subject to the study?

5. What are the spatial and geographical limits of the research and studies published in the sample journals subject to the study?

6. What are the languages used in the research and studies published in the sample journals subject to the study?

7. What is the nature of the completed research and studies covered by the sample journals subject to the study?

8. What are the practical, media, and communicative elements covered by the research and studies in the sample journals subject to the study?

9. What are the media and communication fields of the studies and research published in the sample journals subject to the study?

\subsection{Sample of the Study}

The selected sample was as follows:

1. Algerian Communication Review: Faculty of Media and Communication Sciences University of Algiers 3-Algeria. (https://www.asjp.cerist.dz/en/PresentationRevue/437).

2. Journal of Mass Communication Research: Faculty of Mass Communication - Al Azhar University - Egypt (https://jsb.journals.ekb.eg/).

3. Al- Bahith AL - A'alami (Media Researcher Journal): Faculty of Mass Communication University of Baghdad - Iraq. (https://abaa.uobaghdad.edu.iq/index.php/abaa). 
4. Arabian Journal of Media and Communication: Saudi Association for Media and Communication - King Saud University - KSA (https://samc.ksu.edu.sa/node/1126).

The study began in August 2021. The samples included 32 issues with an average of eight issues per journal from 2017-2020, taking the following considerations into account:

- Application of scientific standards in the field of arbitration and publication.

- Available website for the journal.

- Publication by a university institution.

- Specialization in the field of media and communication sciences.

- Presence of a scientific or specialized editorial board for the journal.

- Application of scientific standards in the field of arbitration and publication.

\subsection{Methodology of the Study}

The study relied on the methodology of a survey through description and analysis, as well as the content analysis tool. The content analysis was best defined by Berlson , and his definition has been adopted by studies since 1952. He defined the content analysis as: "A research method or tool for the objective and quantitative description of manifest content of a media message in an orderly manner" (Berlson, 1952).

\section{Analysis and Interpretation of Results}

This part of the study covers the results achieved by analyzing the content of a sample of scientific journals specializing in media and communication sciences in the Arab region, through explanation, interpretation, and representation using tables and figures.

\subsection{Number of Items of Research Published in the Sample of the Analytical Study}

Table 1: Number of items of research in the sampled studies

\begin{tabular}{|l|c|}
\hline Magazines & Number of research topics \\
\hline Algerian Communication Review & 95 \\
\hline Journal of Mass Communication Research & 104 \\
\hline Media Researcher Journal (AL - Bahith AL - A'alami) & 69 \\
\hline Arabian Journal of Media and Communication & 70 \\
\hline Total & 338 \\
\hline
\end{tabular}

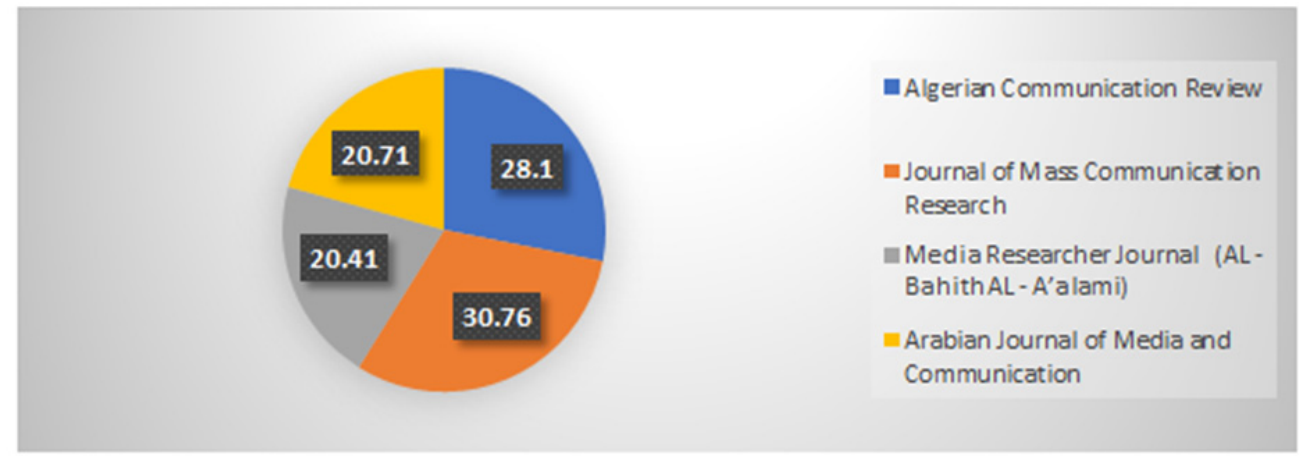

Figure 1: Percentage of research published in all journals 
- The analytical study revealed the number of items of research published in the journals subject to analysis, as follows:

Journal of Mass Communication Research, which is a specialized scientific periodical issued by the Faculty of Mass Communication at $\mathrm{Al}$ Azhar University, took the lead with 104 pieces of research at $30.76 \%$, followed by the Algerian Communication Review, a national hexagonal, refereed, and semi-annual journal issued by the Faculty of Media and Communication Sciences at the University of Algiers, with 95 items of research at $\mathbf{2 8 . 1 0 \%}$. This was followed by the Arabian Journal of Media and Communication, a semi-annual, refereed, scientific journal specializing in media studies and human communication research, issued by the Saudi Association for Media and Communication at King Saud University, with 70 items of research at $20.71 \%$, followed by the Journal of Media Researcher (AlBahith AL - A'alami), a quarterly, scientific, refereed journal issued by the Faculty of Mass Communication at the University of Baghdad and ranked fourth with 69 items of research at $20.41 \%$. (Tableı \& Figure1).

\subsection{Types of Research Published in the Sample of the Study}

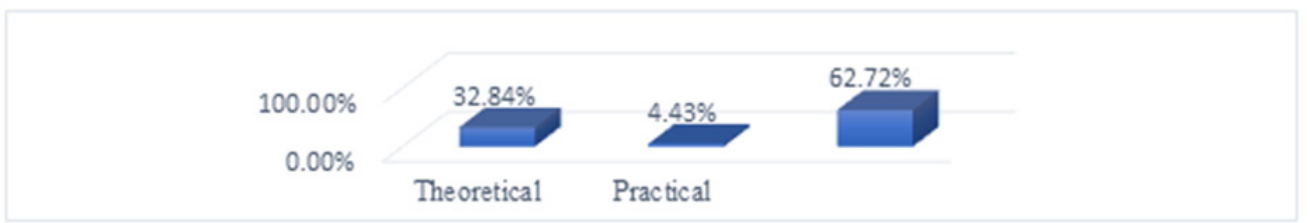

Figure 2: Types of research published in the total sample.

- With regard to the nature of the research published in the sample of journals subject to the study, theoretical and field research took the lead with $62.72 \%$ against $32.84 \%$ for theoretical research, a percentage that reveals the dominant tendency of media research in the Arab countries compared with the theoretical framing of research, while the pure field studies do not exceed $4.43 \%$.

\subsection{Tools Used to Collect the Data of Published Researches}

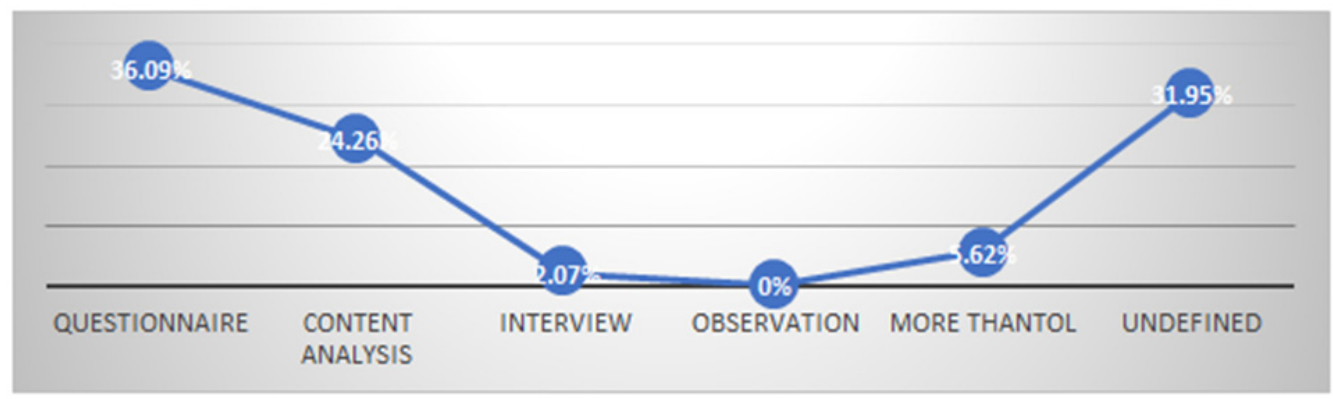

Figure 3: Data collection tools in the study in the total sample

- Figure 3 shows the research and data collection tools used in the sample subject to the study. The questionnaire was the tool most used in completed researches at $36.09 \%$, followed by the content analysis tool at $24.26 \%$, and the interview tool with a very low percentage of $2.07 \%$. Many studies indicated the high dependence on the questionnaire tool 
in the media and communication research.

5.4 Theories and Approaches Used in Published Researches and Studies

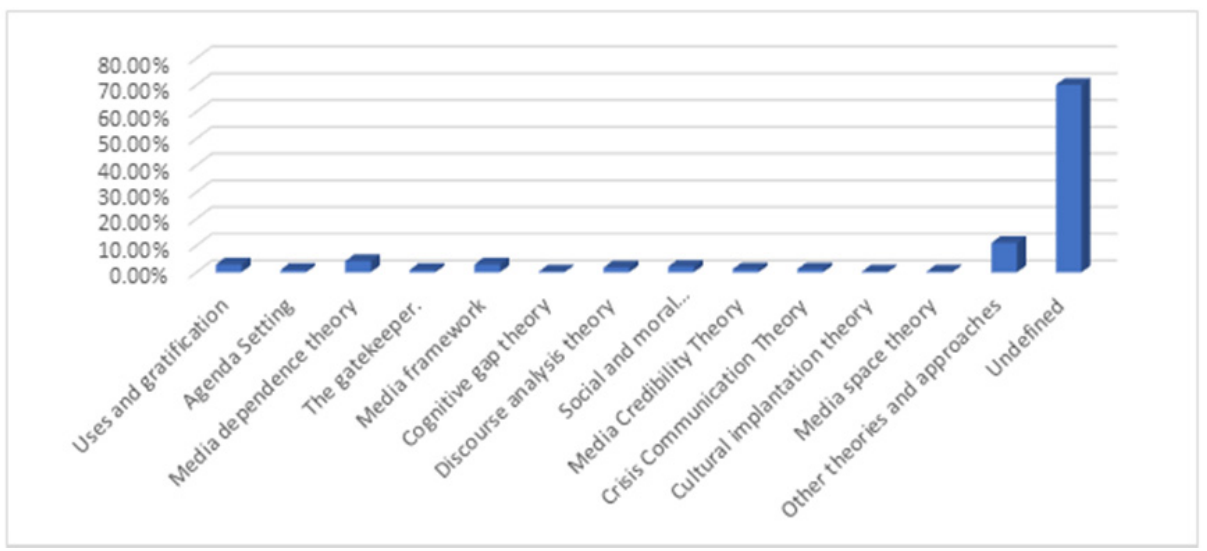

Figure 4: Theories and approaches in the total sample

- With regard to the theoretical approaches and methods used in the research and studies published in the whole sample subject to analysis, the results revealed, as shown in Figure 4, that $70.11 \%$ of the published research failed to adopt any theoretical approach. This percentage shows the validity of results, confirmed by previous studies, showing that media and communication research in Arab countries consists of impressionistic studies that lack scientific approaches framing the scientific research in this field. With regard to the most important approaches adopted in other published research, we find that the "Media Dependency Approach" reached 4.13\%, the "Uses and Gratifications Approach" reached 2.95\% (equaling the percentage for the "Media Framework Approach"), followed by the "Media Social Responsibility Approach" at 2.07\% (equaling the approximate percentage for the "Discourse Analysis Approach").

\subsection{Geographical Limits of Published Research and Studies}

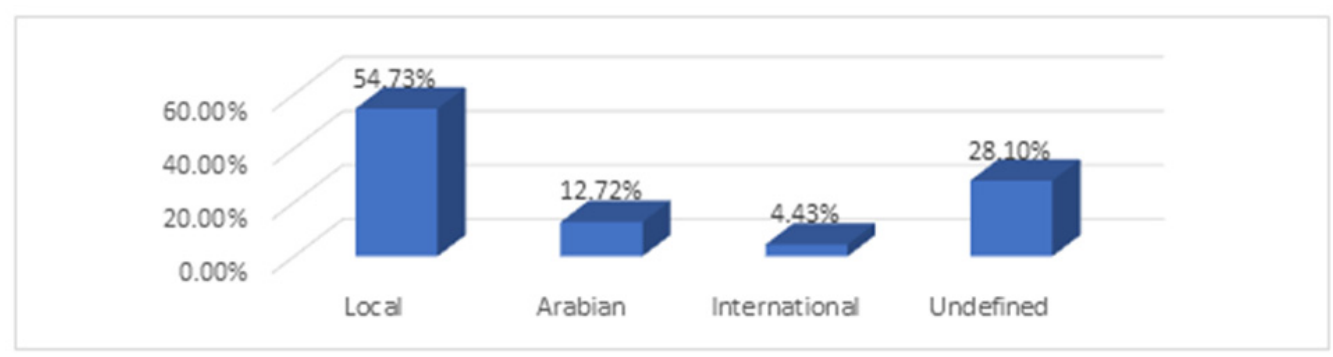

Figure 5: The geographic locations of the research in the total sample

- With regard to the geographical scope of research published in the whole sample, Figure 5 
shows that a large percentage, amounting to $54.73 \%$, of the research covered local issues, with the Arab dimension ranking second with a low percentage amounting to $12.72 \%$, followed by the international dimension with $4.43 \%$.

\subsection{Languages Used in Published Research and Studies}

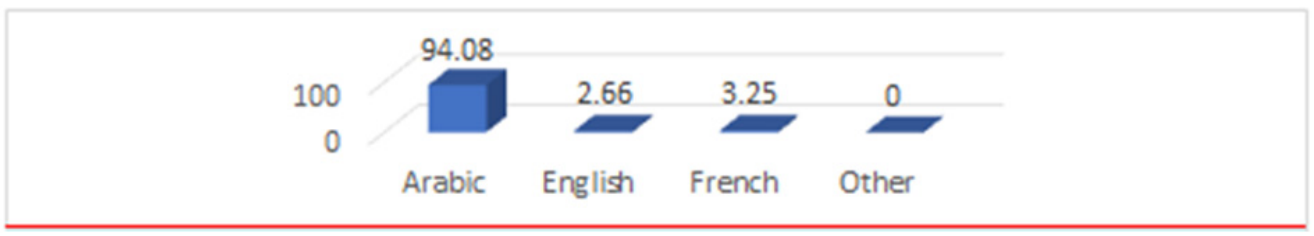

Figure 6: The language used by the research published in the total sample

- With regard to the languages used in the scientific research published in the whole sample of journals subject to analysis, Figure 6 shows that the Arabic language has the highest percentage with $94.08 \%$, followed by French with $3.25 \%$, and then English at $2.66 \%$. Such percentages do not reflect the nature of linguistic map of the region in terms of the English language. This result is ascribed to the high usage rate of French in the Algerian Communication Review, and the robust presence of the French language in Algeria, where it dominates various activities, including scientific research.

\subsection{Number of Participants in Published Research}

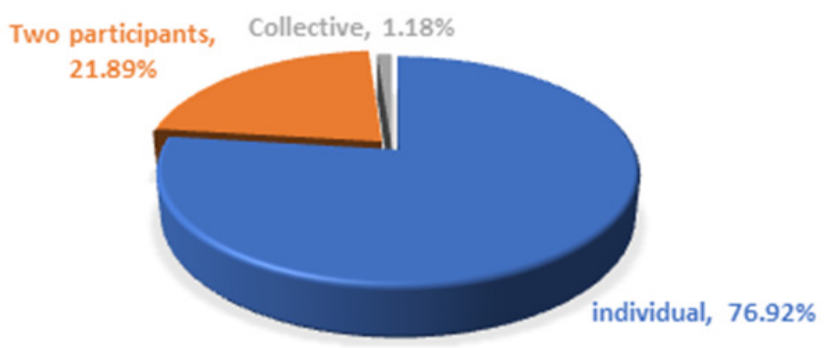

Figure 7: The number of participants in published research in the total sample

- With regard to the number of participants in the published research in the whole sample, Figure 7 indicates the predominance of individual research at $76.92 \%$, followed by bilateral research at $21.89 \%$. On the other hand, joint research did not exceed $1.18 \%$, confirming the predominance of individualism in research. This is because much of this research is submitted for publication for the purpose of promoting and developing scientific and professional careers and some universities approve of a low percentage of joint research for scientific promotion.

These results can be justified by the lack of research centers that encourage the use of teamwork in research. (Kamel, 2007). 


\subsection{The communication Elements studied in the Sampled Research}

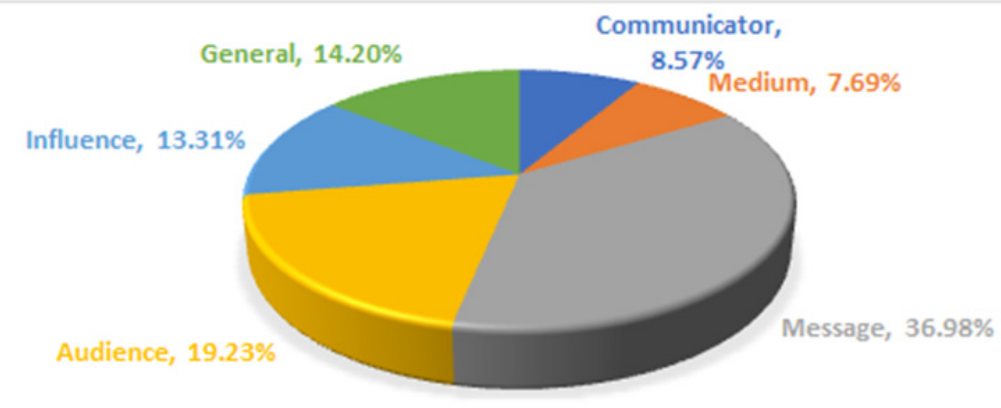

Figure 8: Elements of the communication process studied in the total sample

- Figure 8 shows the overall results regarding the media process elements in terms of the focus of the published studies. The study revealed that research focusing on the message element took the lead, at $36.98 \%$, followed by research focusing on the audience element, at $19.32 \%$, and research focusing on the influence element, which ranked last at $13.31 \%$. In general, the overall results show that the whole sample of research focused on all elements of the media process, albeit with varying percentages.

\subsection{Areas of Communication and Media Studied in the Published Research}

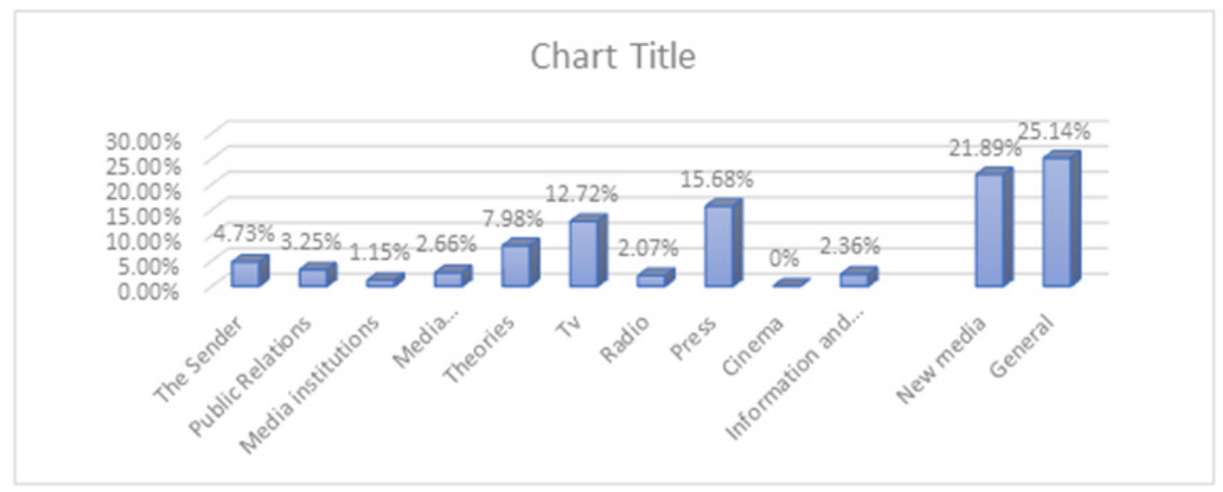

Figure 9: Areas studied in the research published in the total sample

- The analytical study (Figure 9) shows that the media and communication areas that received the attention of the research published in the sample subject to analysis were varied, including all media activities and media and communication topics. A total of $21.89 \%$ of such research covered issues related to new media, compared with $15.68 \%$ for journalism, $\mathbf{1 2 . 7 2} \%$ for television, and $7.98 \%$ for theories. These are logical results, justified by the fact that research in many countries tends to pay regard to the phenomenon of new media, with a decline in traditional media research (Kamel, 2004). The most important observation that can be made from the above figure is the lack of focus on cinema research in the sample. We 
believe that this is due to the fact that researchers consider this field to be related to the field of arts, with cinema not being taught in media faculties and departments, and research or theses on the cinema being rare compared with other fields of communication and media science.

\section{Overall Results of the Analytical Study}

The analytical study of the trends shown in the research sample subject to analysis has enabled the researcher to draw some important conclusions, summarized as follows:

1. There is a difference in the number of research works published in the issues of the selected sample (the number of topics in each issue).

2. There is a tendency to connect the theoretical and field aspects of the published research.

3. There is a predominance of the questionnaire as a research and data collection tool in the published research sample, followed by use of the content analysis tool.

4. The research projects published in theoretical approaches are not framed in most research works published in the study sample.

5. There is a predominance of the local dimension in the published studies, while the amount of Arab and international researches remains small.

6. Arabic is the language most used in the research works in the study sample and there is a lack of research done in foreign languages, although the sampled journals accept this.

7. There is a predominance of individual research work in the sample, compared with joint research work.

8. Most of the published studies focus on content, followed by the audience, and finally the influence, with a lack of research on the medium and the sender.

9. Journals in the sampled research tend to focus on new media rather than traditional media such as press and television.

\section{Discussion}

The present research tackled a deep analysis on the trends of media and communication research in specialized scientific Arab journals. It has attempted to answer the main question: What are the trends of media and communication research in Arab countries, as represented in a sample of specialized scientific journals in this field of knowledge and science? To this end, the study has relied on several previous researches, summarized and presented the conclusions, and their results were compared to those of this study. Our results regarding those studies reached some conclusions, some of which are the following:

Journals specialized in communication and media sciences are concerned with the theoretical and field investigation of the topics in question, after they were previously, and for a long time, concerned with impressionist and descriptive researches that lacked measurement. Moreover, many of those researches had no framework for approaches, as emphasized by previous studies (Layadi, 2016; Falak \&La'Lawi, 2018).

Studies published in the sample journals were on local topics. We believe this reduces the opportunities of generalizing their results. Moreover, the significant proportion of topics in Arabic in big amounts restricts the spread of those results, and limit them only to the geography or the country in which the study was performed.

In addition, the majority of published researches, $76.92 \%$, were carried out by individuals, implying that research into communication and media sciences has a personal motivation; most important of all is job promotion, and the increase in responsibilities and functions. The scientific output and objectives of institutions to which those scholars are affiliated have shown to be marginal motives. Sarraj (2018) case study also found that $79 \%$ of studies were performed by individuals. Moreover, a study by Kamel (2007), in which two journals from Egypt and the United States were 
compared, found that jointly authored researches formed $8.6 \%$ of the Egyptian journal content, while this percentage was $47 \%$ for the American journal.

The study also found that research in recent years has shifted to new media. One concern is whether this tendency has resulted from the attraction to new media at the expense of neglecting research into traditional media such as newspaper, radio and television. Many studies have stress that these media were still needed. This notion can be made evident across the stages of the COVID-19 pandemic, where those media have been used by a significant proportion of people. Surveys (Edelman Trust \& Barometer, 2020), research and studies confirm the superiority of media tools over internet websites and social networking sites as reliable sources for covering reliable news for the public (Simon \& Florian, 2021).

The present study also revealed several positive transformations in media and communication research, including:

- Developing and updating websites for the journals investigated in this study or others.

- Focusing journals impact factor, most importantly "Arab Impact Factor" that measures the significance of the refereed scientific journals that are published in Arabic. (https://www.arabimpactfactor.com/).

- Regulating publication, and taking care of framing journals by scientific consultant committees and by the specialized referring commissions.

- Increasing the interest of some journal supervisors in joining international data indices such as Scopus as well as Journal of Arab Media and Society which is issued by the American University of Cairo. (https://www.arabmediasociety.com/).

In conclusion, we believe that the present study is an important scientific addition into media and communication research in the Arab region, by adopting samples from different parts of the Arab world, especially as it has been authored in English. We hope to disseminate the study and to introduce media and communication research that has been conducted in this part of the world.

\section{References}

Abdel Rahman, A. (2002). Critical Theory on Communication Research. Cairo: Dar El Fikr Al Arabi.

Abdel Rahman, A., Seddik. R. (2019). Journalism Research. Cairo: Al-Arabi Publishing and Distribution.

Al khalaifi, A. (2008). Dictionary of Media Terms. Alexandria: Dar Al Marefa Al-Jameya.

Al-badawi, T. (2015). Theoretical and Methodological Treatment of User Participation in the Digital Public Sphere a Critical Analytical View of Recent Scientific Trends. Conference: Methodological Problems for Social Networks,

Algerian Communication Review. [online]. Available at:< https://www.asjp.cerist.dz/en/PresentationRevue/ 437>.ISSN: 4479-1111.

Al-sarraj, S. (2018). Trends of Scientific Research in the Specialized Journalism, Journal of the Media Researcher as a Model-Survey Study. In Journal of the Media Researcher, Vol. 10, No. 39, p. 10- 28. ISSN: 8005-1995.

Arab Impact Factor. [online]. Available at : <https://www.arabimpactfactor.com/>.

Arab Media and Society. [online]. Available at: $<$ https://www.arabmediasociety.com/>.

Arabian Journal of Media and Communication. [online]. Available at:< https://samc.ksu.edu.sa/node/1126>. ISSN: 1658-3620.

Bakhit, S. (2010). Recent Trends in Journalism - A Survey and Critical Review of the Most Prominent Trends Prevailing.in Journalistic Studies. in Arabian Journal of Media and Communication, No. 6, p.57170.ISSN:1658-3620.

Bakhit, S. (2016). Theoretical and Methodological Problems of Social Media Research - An Analytical Reading. In Arabian Journal of Media and Communication, No. 13, p.143-196. ISSN: 1658-3620.

Berlson, B. (1952). Content Analysis in Communication Research, Michigan: Free Press, 1952.

Dacheux, E. (2009). Les SIC approche spécifique d'une recherche en communication mondialisée. Les sciences de l'information et de la communication, CNrs éditions, collection les Essentiels. (p,9-36).

Devillard, J., Marco, L. (1993). Ecrire et publier dans une revue scientifique. Paris: Les Editions d'Organisation. $(\mathrm{P}, 127)$.

Edelman Trust Barometer, Special Report (2020) : Trust and The Coronavirus . [online]. Available at :< 
https://www.edelman.com/research/2020-edelman-trust-barometer-special-report-coronavirus-and-trust>. Ezzat, M. (2008). Glossary of Communication Terms. Beirut: Crescent House and Libraries.

Falak, A., La'lawi, K. (2018). Methodological Problems in the Doctoral Thesis of Media and Communication Sciences. In Algerian Journal of Communication and Journalism, No. 8, p. 91 - 104.ISNN:2353-0383.

Filder, R. (1997). Mediamorphosis: Understanding. California, London, New Delhi: SAGE Publications, 1997.

Houdayer, G. (2020). Coronavirus: le temps passé devant la télé par les Français atteint un nouveau record. [Online]. Available at:>https://www.francebleu.fr/infos/medias-people/coronavirus-le-temps-passe-devantla-tele-par-les-francais-atteint-un-nouveau-record-1588603876 >.

Journal of Mass Communication Research. [online]. Available at:< https://jsb.journals.ekb.eg/>. ISSN: 1110-9297.

Kaabache, A. (2016). Trends in Electronic Media Research in Algeria from 2005-2010 - Analytical Study.in Journal of Social Studies and Research, No.15, p. 61-72. ISNN: 2353-9555.

Kamel, M. (2007). Trends in Journalism and Media Research in America and Egypt - An Analytical and Exploratory Comparative Study of the American Journalism and Media and the Egyptian Journal of Media Research. Paper presented at the Fourth Scientific Conference of Akhbar El Yom Academy. Cairo.

Media Researcher Journal. [online]. Available at:< https://abaa.uobaghdad.edu.iq/index.php/abaa>. ISSN: 80o51995.

Nasr, H. (2015). Trends in Research and Theorization in New Media - An Analytical Study of Scientific Production Published in Refereed Journals - Research. Paper presented at the international scientific conference Social Media Applications and Problematic Methodology. College of Media and Communication, Mohammed Bin Saud Islamic University, presented on the 11th of March 2015.

Riyadh, Saudi Arabia.

Shoman, M. (2004). Problems of Discourse Analysis in Arab Media Studies - Egyptian Studies as a Model. In the Scientific Journal of the Faculty of Arts, 2004, Vol.2, No.53, p.229-291.ISSN:1110-4341.

Shoman, M. (2015). Media Research Crisis. In Al Youm Al Sabea Newspaper, December, 13, 2015.

Simon, L. Florian, S. (2021). La confiance envers les médias et la désinformation en contexte de pandémie. Université Laval: Centre d'études sur les médias, Université Laval-Sainte-Foy (Québec).

Specialized Scientific Journals: [online]. [2021-02-15]. Available at: <https://www.britannica.com/topic/magazinepublishing/>.

Walken, E. (1986). Introduction to Means of Communication. Cairo: Cairo Commercial Press.

Walter, J. et al. (2009). Dynamiques des recherches en sciences de l'information et de la communication. ze édition revue et complétée. Conférence permanente des directeurs des unités de recherche en sciences de l'information et de la communication. [online]. [2020-12-15]. Available at: $<$ https://hal.univ-lorraine.fr/halo1885229/file/dynamiques-recherches-en-information-communication-190627.pdfs. 